\title{
A IDEIA DE VERDADE NA FOTOGRAFIA DO SÉCULO XIX: OS TEXTOS DE A ARTE PHOTOGRAPHICA
}

\author{
Francisca Ferreira Michelon*
}

\begin{abstract}
Resumo: A partir do texto de uma novela escrita no século XVIII e citada em uma revista do século XIX, A Arte Photographica, o estudo observa que a antiga obra de ficção antecipa em mais de um século um dos primeiros processos fotográficos, só possível de ter sido inventado em meados do século XIX. Sugere-se que a predição inspirada pela novela possa residir na presença de uma ideia que atravessou os séculos em questão. No campo da história das ideias, emprega-se o uso que Baumer (1990) faz do "cientismo" e do realismo no pensamento europeu para propor a ideia de veridicus visual, aclarando, por meio deste o desejo de uma representação do mundo feita pela máquina.
\end{abstract}

Palavras-chave: Fotografia, História das ideias, Cientismo, Realismo fotográfico.

Abstract: From de novel written in the eighteenth century and mentioned in a magazine of the nineteenth century, "A Arte Photographica", the study notes that the ancient fiction anticipates for over a century one of the earliest photographic processes that could only have been invented in the mid-nineteenth century. It is suggested that the prediction that inspired this novel may reside in the presence of an idea that crossed these centuries. In the field of history of ideas is employed the use that Baumer (1990) makes of the "scientism" and realism in European thought to propose the idea of visual veridicus, clarifying through of a representation of the world made by the machine.

Keywords: Photography, History of ideas, Scientism, Photographic realism.

* Professora efetiva do Programa de Pós-Graduação em Memória Social e Patrimônio Cultural do Instituto de Ciências Humanas da Universidade Federal de Pelotas. Doutora em História PUCRS. 
| 140 |

A ideia de verdade na fotografia...

\section{Introdução}

Uma antecipação literária. É assim que a historiadora Marie-Loup Sougez (2001) dá início ao primeiro capítulo do seu compêndio sobre a história da fotografia. Diz a autora: "a imaginação se antecipa a qualquer descoberta científica" (p.16). E, após preambular o fato, classificando-o como ficção científica, apresenta o conteúdo da novela do médico e escritor francês Tiphaigne de la Roche, que viveu entre 1729 e 1774. Dentre as várias obras escritas por ele, Sougez cita esta: os relatos de um viajante de nome Giphantie que visita e se aventura por lugares delirantes, nos quais a imaginação do autor fantasia possibilidades.

A surpresa expressada por Sougez (2001) não é superlativa: o conteúdo da novela ainda surpreende e provoca curiosidade sobre o fato de que uma invenção como a fotografia pudesse ter sido aludida um século antes da sua ocorrência. Foi tal possibilidade o que se buscou verificar neste ensaio, bem como o que estaria por trás da motivação que levou Tiphaigne de la Roche a inserir na sua novela uma descrição tão semelhante aos processos fotográficos do século XIX. Sugere-se que tenha sido a vigência de uma ideia, forte, antiga e compartilhada, de que se poderia fixar a aparência das coisas, com tamanha exatidão que a própria realidade pareceria, de tal maneira, duplicada. Advogase que o advento do pensamento científico moderno colaborou para isso. E, na continuidade, espera-se ver como se comporta essa ideia por meio das matérias publicadas na revista portuguesa $A$ Arte Photographica que, apesar de ter durado apenas 23 números mensais, conseguiu ilustrar o pensamento vigente sobre os avanços, os desalinhos e, sobretudo, o uso das técnicas empregadas para obter imagens fotográficas nas duas últimas décadas do século XIX. Por conseguinte, este periódico de vida curta apresenta-se, na atualidade, como um compêndio hábil em esboçar o que vinha a ser a ideia de fotografia durante um período no qual algumas técnicas já estavam consolidadas e muitas de suas aplicações já se garantiam no então mercado das imagens. 
Na já citada obra de Sougez, a autora destaca na novela de Tiphaigne de la Roche o trecho que narra o momento em que o protagonista encontra, nos desertos ao norte da Guiné, um jardim inexplicável. A sua visita ao lugar é acompanhada pelo governante, que lhe mostra e explica as peculiaridades fantásticas do jardim, dentre elas, um subterrâneo no qual há paisagens que parecem ser reais. Então, o governante explica que "os espíritos elementares", os habitantes autóctones do jardim, precários na arte da pintura, estavam buscando, por meio dos conhecimentos físicos da natureza, fixar as imagens fugazes que a luz refletida por todos os corpos forma sobre as superfícies polidas. Assim, os espíritos elaboraram um líquido viscoso e delicado com o qual cobriam as telas de pintura, colocando-as, neste estado, imediatamente, na frente da cena que desejavam pintar. Após breve tempo, a tela era retirada e guardada em lugar escuro por uma hora até que a emulsão secasse. Na tela seca, o que se via era exatamente o que diante dela se havia encontrado uma hora antes, com todas as minúcias da realidade, ali fixado para além do presente. Debalde tão prodigioso sucesso, o invento ocupava a atenção dos espíritos elementares que discutiam os aspectos físicos da matéria viscosa, tanto na sua preparação como na sua utilização.

A curiosa passagem dessa novela, destacada por Sougez (2001), evidentemente para além da curiosidade, propõe a reflexão sobre a possibilidade de alguns dos inventos científicos terem sido, antes da ciência, imaginados como alegoria. Já se sabe sobre isso, de modo que em tal aspecto não se encontra qualquer novidade.

O curioso é que, já no século XIX, essa parte da novela do médico francês era conhecida e causava interesse. Na revista A Arte Photographica, publicada na cidade do Porto, Portugal, nos anos de 1884 e $1885^{1}$, houve uma matéria em que a novela é comentada. Na seção intitulada A Legenda da Photographia, o cronista, que não

\footnotetext{
${ }^{1}$ A edição que se empregou neste texto é o fac-símile publicado pelo Centro Português de Fotografia em 2001, em dois volumes correspondendo, respectivamente, aos anos de 1884 e 1885. A linguagem das citações diretas foi atualizada para o português contemporâneo pela autora.
} 
|142 |

A ideia de verdade na fotografia...

se identifica, comenta a disputa pela primazia do invento entre ingleses e franceses, apresentando, com ironia, a preocupação de alguns em encontrar uma autoria em passado remoto. E após um prelúdio prolixo, entabula o histórico das pequenas e grandes descobertas no campo da física e da química que redundaram nas primeiras técnicas fotográficas, para só depois, mencionar a rara literatura, sob esse início:

Em todas as épocas surgem estranhos espíritos, cuja
razão quase perturbada parece antever o futuro,
através de fantásticas alucinações. Cyrano de Bergerac
tinha adivinhado os balões um século antes de
Montgolfier e, em 1760, Tiphaine ${ }^{2}$ de la Roche, num
livro singular que mandou imprimir em Cherburgo,
sob o título anagramático de Giphancia, contando
de um modo burlesco as suas visões, as suas crenças
ou os seus conhecimentos, descreve os processos
fotográficos, há pouco descobertos, tais como são hoje
praticados, em uma passagem muito curiosa para que
nos dispensemos de a reproduzir (p. 219)

Comparando o texto da revista com o de Sougez (2001), tem-se no mais antigo o local de publicação da novela, bem como o ano exato. O cronista é preciso e detalhado na descrição, reproduzindo o seguinte parágrafo da obra citada, no qual o gênio elementar conduz o viajante, que aporta no lugar após perder-se em uma tempestade, pelo castelo e cercanias plenos de surpresas e segredos. Assim, explica o gênio:

[...] os quadros de luz refletidos dos diferentes corpos fazem quadros e pintam os corpos sobre todas as superfícies polidas, sobre a retina, por exemplo, sobre a água, sobre os espelhos. Os espíritos elementares tentaram fixar essas imagens passageiras, compuseram uma matéria muito sutil, muito viscosa e muito rápida

\footnotetext{
${ }^{2}$ Foi mantido o erro de grafia que constava na Revista: foi suprimido o $g$ do nome do médico.
} 


\begin{abstract}
em secar e em endurecer, com a qual um quadro é feito num abrir e fechar de olhos. Estendem essa matéria sobre um pedaço de tela e apresentam-na aos objetos que se pretende pintar. O primeiro efeito da tela é o mesmo do espelho, veem-se nela todos os corpos próximos ou afastados, de que a luz pode trazer a imagem. Mas o que o espelho não poderia fazer, a tela, graças à camada viscosa retém a imagem dos objetos. $\mathrm{O}$ espelho mostra-nos fielmente os objetos, mas não conserva nenhum. As nossas telas não os reproduzem menos fielmente e conservam-nos todos. (p.217)
\end{abstract}

Com essa primeira explicação, a personagem de Tiphaigne antecipa em 100 anos a invenção. Na continuidade, surpreende ainda mais o leitor do presente ao descrever a qualidade das imagens "pintadas":

Uma hora depois a camada está seca e temos um quadro tanto mais precioso quanto é certo que nenhuma arte lhe poderá imitar a verdade e que o tempo de nenhum modo o pode estragar. Nós vamos à fonte mais pura, ao próprio corpo da luz, tirar as cores que os pintores extraem das diversas substâncias que o tempo nunca deixa de alterar. A precisão do desenho, a variedade da expressão, o traço mais ou menos, sorte, a variação nos tons, a regra da perspectiva, tudo, tudo isso nós abandonamos à natureza que, com essa marcha segura que nada desmente, traça sobre as nossas telas imagens que se impõem e nos fazem duvidar a razão se o que chamamos realidade não são outras espécies de fantasmas que se nos apresentam aos olhos, aos ouvidos, ao tato, a todos os sentidos ao mesmo tempo. (idem)

O cronista, motivado pela tremenda semelhança entre as pinturas dos gênios elementares e o processo do colódio (úmido ou seco), conjetura possibilidades para explicar a antevisão do escritor: 
$|144|$

A ideia de verdade na fotografia...

Não teria Tiphaine de la Roche, tão erudito em coisas maravilhosas, lido no Livro dos Metaes, publicado em 1566 pelo alquimista Fabricio, que toda a camada produzida por uma lente sobre uma camada de prata córnea (cloreto de prata) nela se fixavam em preto as parte iluminadas, em cinzento as de meias tintas e em branco as sombras e não será do mesmo fenômeno que fala um alfarrábio de que faz menção Jovard, o sábio de Bruxelas e que trazido do alemão há trezentos anos, trata muito claramente da fotografia? Para encontrar nesses sonhos e nesses fatos entrevistos pelos alquimistas, investigações seriamente científicas para a fixação da imagem, é necessário chegar até Charles e Wedgwood. (p.221)

Ao buscar as referências que poderiam ter sugerido o invento ainda não inventado à imaginação de Tiphaigne, o cronista conclui que as possibilidades efetivas de obter uma imagem em câmera escura, sobre superfície fotossensível e fixada para além do momento da sua obtenção era fato que só seria possível no século posterior ao do escritor.

Não é difícil entender o tamanho da curiosidade que a antevisão do médico escritor causou nos fotógrafos dos anos oitocentos. Em meados da década de 1880 os processos fotográficos para obtenção de negativos ainda eram feitos com a dispersão de líquido viscoso contendo a substância fotossensível sobre uma chapa de vidro e, se fosse colódio úmido, a exposição deveria ocorrer imediatamente. A compreensão da fotografia como extensão da realidade era amplamente aceita, como atestam as palavras de Goudmann na seção Apontamentos para a Fotografia Instantânea, do primeiro número da A Arte Photographica: "A fotografia não mente nunca, assim como o espelho plano, e se por acaso vemos em certas paisagens, torres ou chaminés que se abraçam com amoroso amplexo, temos de acusar o operador que não soube servir-se dos aparelhos." (p.2).

Assim, o que se pretende analisar não é a relação entre as fontes que publicaram o comentário da novela de Thipaigne, tampouco se auspicia encontrar algum sentido lógico para explicar 
a ocorrência dessa novela naquele distante século. Deseja-se, apenas, refletir sobre a ideia de fotografia como imanência de um desejo de realidade que se pode guardar para além do tempo imediato.

\section{A fotografia no futuro: uma ideia do passado}

O escritor francês do qual fala esse texto, Charles-François Tiphaigne de la Roche, escreveu muitas novelas em meados do século XVIII, algumas que conspurcam inspiração no fantástico. Entretanto, não compete falar de singularidade no contexto em que viveu. Hábil na criação de conjunturas delirantes revela altas expectativas para o futuro transformadas, na literatura, em circunstâncias de encontro com o mágico. Sua literatura sugere a antecipação de invenções diversas e a novela Giphantie, publicada em francês e traduzida para o inglês ${ }^{3}$, é decisivamente marcada pela previsão de inventos.

No entanto, isso não parece ser uma excepcionalidade. O escritor inglês Brian Stableford lançou em 2007 uma coletânea na qual traduziu nove contos franceses, publicados entre 1768 e 1902, considerados proto ficção científica e, dentre os quais, se destacam algumas previsões como o transplante de coração e o raio laser. Outros temas lançados ao futuro indicam, pelo contrário, especulações literárias sem qualquer antevisão dos caminhos da ciência e dos inventos. Portanto, as especulações sobre as relações entre ciência e ficção, expressadas não só na literatura, constituem um campo de pesquisa cujo principal recorte temporal estende-se do século XIX ao presente, largo período de tempo que foi marcado, sobretudo, pelas intensas mudanças promovidas nas sociedades em decorrência das revoluções industriais e seus resultados.

\footnotetext{
${ }^{3}$ A tradução para o inglês, realizada no ano seguinte ao seu lançamento na França, mudou, ligeiramente, o título: Giphantia, alterando o anagrama proposto pelo autor. Essa versão também incluiu uma nota explicativa.
} 
|146 |

A ideia de verdade na fotografia...

Visto desse modo, naturaliza-se o efeito de Giphantie, sem precisar explica-lo. Tampouco sente-se, diante desta naturalização, motivo para investigar a origem de tal previsão de uma forma de registro do mundo que iria, determinantemente, mudar a percepção visual do homem ocidental e inaugurar uma forma de documento ainda hoje surpreendente sob muitos aspectos. Todavia, permanece a curiosidade sobre a publicação do texto na Arte Photographica que expressava, então, a visão do século XIX sobre a fotografia e vivia, justamente, o momento inicial do estarrecimento conceitual de um mundo (ressalta-se: parte do ocidente) impactado pelos inventos.

A ideia de fotografia naquele momento tinha contornos muito claros: tratava-se de um conjunto de técnicas que avançava conforme problemas específicos eram solucionados. Para a maioria dos fotógrafos que vendiam os seus serviços produzindo fotografias, fotografar bem era obter uma matriz negativa com contraste suficiente para ser copiada em positivo, que gerassem positivos nítidos e com bom contraste e nuances entre as áreas escuras e claras.

Se, em parte, os problemas já não eram os mesmos da sua origem, a promessa de um mundo representado como se fosse a visão obtida em um espelho mágico, que não esvanecesse o que diante dele se colocava, ainda estava por se cumprir. A prática da fotografia era árdua. As expectativas, os quereres e a concretude do que se conseguia não se coadunavam em resultados plenos, na maioria das vezes, nem mesmo eram obtidos resultados satisfatórios. Com frequência, mesmo quando os procedimentos técnicos eram rigorosos, os imprevistos das reações químicas e a falta de domínio sobre os componentes e materiais empregados, resultavam em imagens de pouca ou nenhuma acuidade visual ou, ainda, em imagens deléveis, que desapareciam em curto espaço de tempo. Para a maioria dos fotógrafos a preocupação com o seu produto fotográfico não é que este durasse algumas décadas, mas alguns meses, de modo que os clientes fossem atendidos em suas expectativas mínimas.

Pode ser que em tal situação, os visionários do futuro da fotografia valessem em menor grau do que os que a visionaram 
no passado. Sobre isso, uma crônica publicada na edição nำ da Arte Photographica pode ser representativa da visão de uma fotografia que não sugere o devaneio, tão apenas, mas parece estar impregnada, naquele momento, de especulações inexatas, que transitavam entre o despropósito e o equívoco.

A crônica, publicada nessa e desdobrada na edição n⿳011, chamou-se A Photographia do Futuro e relatava com ironia o caso de um fotógrafo amador, de lugar não nominado, mas, segundo o autor, de "um cantinho de uma das nossas províncias" que possuía uma imaginação sensível comparável à "sensibilidade das chapas gelatinadas de Wainwrigth" (p.201). O início da crônica já indica o tom irônico com que é o contado o caso que, verdadeiro ou não (provavelmente), traduz alguns aspectos do pensamento da época. Dentre as excentricidades do fotógrafo, estava a de especular o que seria o futuro da fotografia: "Qual o papel que lhe estava destinado? A que ponto poderia subir sua importância com relação às ciências, às artes e à indústria?" (idem). Então o cronista conta a visita feita ao fotógrafo de avançada idade e imaginação

\begin{abstract}
Penetramos em seu laboratório com o religioso respeito com que se penetra em uma velha e silenciosa catedral e sentíamo-nos pequenos ao perpassar por entre seus frascos enormes, que tomavam para nós as extraordinárias proporções de gigantescas colunas góticas. Esta disposição do nosso espírito tinha a sua origem no entusiasmo e profundo respeito com que o nosso amigo nos falava da grande arte, da única arte. [...] (p. 202)
\end{abstract}

Os visitantes foram conduzidos pelo velho fotógrafo até uma sala onde anunciou que apenas ele entrava, salvo naquele dia, quando abria exceção por reconhecer que a Photographia Moderna ${ }^{4}$ tinha seus olhos colocados no futuro da grande arte. Então mostrou um frasco com um líquido que anunciou ser capaz de ${ }^{4}$ Nome da editora de A Arte Photographica, portanto, deduz-se que o cronista
seja um dos editores e que os visitantes também o eram. 
|148 |

A ideia de verdade na fotografia...

fazer fotografias instantâneas, explicando o processo que consistia em colocar um pouco de líquido na palma da mão, esfregando-as até que secasse. Depois, com uma bofetada na face do retratado, obtinha-se a imagem, que vinha a ser processada como uma placa isocromática. $\mathrm{O}$ articulista informa que os visitantes declinaram do convite para experimentar o processo.

Outros processos da mesma natureza fantasiosa foram apresentados, chegando-se no curiosíssimo processo do chapéu, que o velho fotógrafo assim explicou: "Um sujeito vai pela rua, quer fotografar outro e só tem que o cumprimentar tirando o chapéu. Nesta ocasião carrega com o dedo neste pequeno botãozinho que existe na aba e dá-lhe a pose que quiser." (p.204). $\mathrm{O}$ relato desdobra-se elencando aspectos burlescos do discurso extravagante do anfitrião e, finalmente, encerra-se com outra visita, agora ao "Hospital dos Alienados" para o qual foi recolhido, posteriormente, o imaginoso fotógrafo, cada vez mais delirante.

Em capítulo posterior, a revista deu continuidade à crônica na forma de uma carta, dirigida a um dos visitantes daquela ocasião pelo fotógrafo asilado. A carta foi publicada sob o título de "Reclamação Justa" e escrita com o mesmo tom jocoso da crônica antecedente, faz saber sua autoria: o velho fotógrafo inventor. A reclamação do autor dizia respeito a um roubo de invento do qual seria ele a vítima. Contava que descobrira o roubo em um número do Bulletin de la Société Française de Photographie, publicado em novembro de 1884. Nessa publicação anunciava-se que um homem de nome Mendoza apresentou à sociedade o "chapéu fotográfico". O satírico desenrolar da carta parece não ter tido outro fim além do divertimento dos leitores. Toda a história, bem como o personagem possivelmente inventado por um dos articulistas da revista, alimenta, no entanto, a ideia de que o futuro da fotografia poderia ser tão improvável quanto insonhável. Naquele momento, entre processos que se sucediam ou coexistiam, as tentativas em resolver os problemas da técnica ocasionalmente geravam experiências bufas, sobre as quais uma mente razoavelmente criativa poderia encontrar inspiração para o cômico. Resta saber se 
alguém, naquele fin de siècle, imaginou as possiblidades que estão disponíveis a tantos hoje.

\section{Invenções, inventores e ciência}

E se a fotografia acompanhava a ciência, como fruto dela e como especial agente colaborativo, também aí se desenhavam os conflitos. Em seção intitulada Curiosidades Photographicas, com subtítulo Uma palavra à propósito da propriedade das obras photographicas, o articulista narra um caso específico ocorrido durante seção da Academia de Ciências ${ }^{5}$ para exemplificar o limite entre criador e criatura, ou seja, a autonomia que a imagem fotográfica tem em si, que se afasta da mão humana que a fez, permitindo que se dilua a autoria. Conta o autor que o fisiologista Duchenne, de Boulogne, apresentou um álbum de fotografia

[...] no qual ele se propunha a revelar pela análise elétrica e com o auxílio da fotografia as diferentes expressões dos sentimentos que se traduzem na fisionomia pela contração muscular, os movimentos, as linhas, as rugas do rosto, provocando por meio de correntes elétricas a contração dos músculos da face, de modo a obriga-los a falar a linguagem das paixões e dos sentimentos representando pela fotografia cada uma dessas diversas contrações e, por conseguinte das diferentes fisionomias. (p. 177)

O comentarista destaca a originalidade e importância do estudo deste cientista, que o futuro viria a conhecer como tendo sido o pioneiro da neurofisiologia, aludindo que tal investigação não importava "[...] somente à fisiologia, mas, em que as artes plásticas encontrarão ensinamentos preciosos e novos" (idem). No entanto, a questão dramática que o escritor sobressai é que:

\footnotetext{
${ }^{5} \mathrm{O}$ artigo, pelas referências descritas, trata-se de tradução de algum texto em
} francês. Portanto, a Academia a qual o autor refere-se deve ser a Francesa. 
$|150|$

A ideia de verdade na fotografia...

[...] o Doutor Duchenne, caindo na asneira de empregar a fotografia, esses tipos que tanta observação lhe custaram, tantos ensaios pacientes, não lhe pertencem de modo algum. Pouco importa que a Academia de Ciências não the furte os seus aplausos e o reconheça por inventor da ideia, o primeiro mercador de imagens em procura de uma excentricidade explorável pode toma-los, publica-los aos milhares de exemplares e privar, assim, o eminente doutor do fruto do seu gênio, do seu trabalho e das suas despesas. (idem)

O comentarista admitia haver particularidade no caso "[...] no qual a intervenção do aparelho fotográfico não passa de um acidente" (idem) porque o fato de relevo é o invento do médico e o resultado que obtém na contração dos músculos dos seus pacientes. No entanto, reconhece e defende que sem o trabalho do fotógrafo não haveria a imagem tal como é, porque o sucesso da compreensão do resultado de suas manobras científicas só pode ser apreendido na medida em que o fotógrafo inventa a pose, controla o lugar onde a luz incide, opera e seleciona os aspectos do ambiente empregando sua imaginação.

Ora, inscreve-se nesse exemplo a ideia de uma imagem que se apresenta tão independente do seu realizador que o faz sumir, ainda que as qualidades que se preponderem venham do esforço daquele que maneja o aparelho e a cena. A negação da autoria reforça ou retoma a proposição da natureza representando a si mesma, como havia proposto Talbot ao nomear seu processo de "desenhos fotogênicos" ou desenhos feitos pela luz. Embora a preocupação do articulista seja discutir e fundamentar a necessidade de reconhecimento da autoria da imagem fotográfica, o seu discurso revela os contornos difusos de um meio eivado do desejo de ser uma ferramenta para a apresentação da realidade em caráter absoluto, ou seja, para a apresentação do real verdadeiro. Como aprender o real sem perdê-lo? Como mantê-lo tangível quando dele é suprimido volume, massa, cor, sabor? Como afirmalo concreto se apenas o é para os olhos? Trata-se, portanto, de 
reconhecer a possibilidade de uma imagem conceito, um veredicus (o que diz a verdade) sobre o mundo.

O surgimento e fixação da fotografia como invento, produto mercadológico e meio de representação deu-se no Século do Devir que, segundo o historiador Franklin Le Van Baumer (1990) viu na ascensão do historicismo o método de enraizamento das suas convicções. $\mathrm{O}$ autor advoga que o significado da história naquele período não se restringia à finalidade em compreender o passado ou em encontrar nele as anterioridades do presente, todavia inscrevia-se como "a ciência do devir" (p.21). Nas palavras do autor, a história tinha se tornado o "idioma em que quase tudo era explicado", linguagem que se suportava e afirmava o sentido de evolução inscrito em um ambiente de mudanças. E a história parecia ser, na sua circunstancial condição de "rainha das ciências", o sustentáculo do pensamento europeu oitocentista, que fez desse o "século europeu por excelência". Tal sentimento, que alinhava as diferentes nações sob a ideia de ser europeu (e que declinaria em direção ao fim com o advento da Primeira Guerra Mundial), encontrava razões para confirmar o pressuposto de que a força criativa, essência do novo, era um distintivo europeu.

Assim, quando no somatório das décadas já se fazia possível dizer, senão o que foi, ao menos o que era o Século Maravilhoso, Baumer (idem) esclarece que:

\begin{abstract}
Maravilhoso, certamente, mas incrivelmente desordenado também, graças em parte à própria ideia de evolução que ele [Alfred Russel Wallace] e Darwin, simultaneamente, defenderam; e graças também ao fato de se terem habituado a viver num mundo de perpétua evolução ou 'devir'; e também ao crescente aumento das ideias que Arnold citou, e ao crescente 'criticismo', não só da velha cultura da Europa, mas também da nova que, desde a época de Newton, parecia ser, para muitos, a principal esperança do mundo. O século XIX, por mais maravilhoso que seja, foi na verdade, o Século do Devir. (p.22)
\end{abstract}


| 152 |

A ideia de verdade na fotografia...

Porém, não é o devir que explica os procedimentos racionais e racionalizados norteadores do pensamento europeu oitocentista. O que esclarece tal ocorrência é uma confluência de fatores dos quais destacamos, para analisar a fotografia enquanto fenômeno da ideia, o "cientismo", entendido, segundo o argumento de Baumer, como o vestígio supremo do culto da ciência, que se afirma entre os anos de 1820 e 1880, com nuances que se estendem até o final do século. O autor o define como uma "disposição romântica" que buscava explicar o mundo e todas as manifestações que nele se dão, por meio da ciência. E, embora essa fosse uma atitude remanescente do Iluminismo, naquela altura a ciência passava a ser empregada, enquanto conceito, como uma ferramenta para lidar com fatos socialmente invasivos, inéditos e conflitantes, tais como as novas formas de trabalho, de convívio social, de organização da vida nas cidades, de poder, entre outras. E no âmbito dessas circunstâncias, em parte operacionais, é que a ciência triunfa com "[...] sua habilidade para alargar as fronteiras do conhecimento e reduzir o mundo a leis gerais" (p.63). É por meio do "cientismo" que o propósito em se chegar ao conhecimento verdadeiro impõe-se. E é na transversalidade do uso desse conhecimento que o pensamento, científico ou não, passa a buscar e eleger os mecanismos de apreensão da realidade, para firmá-la e racionalizála em preceitos verdadeiros.

A emergência da máquina correspondia e alimentava a expectativa de uma ferramenta superior que consagrava à época industrial a supremacia inaudita do homem sobre a natureza. Os inventos e os inventores distinguiam-se no horizonte assertivo da tecnologia como um benefício, participando, igualmente, do pensamento oitocentista que, no seu todo, encontraria conclusão derradeira no advento do Grande Conflito. Porém, nos densos anos do Século do Devir, dos quais aqueles da década de 1880 foram exemplares sob diversos aspectos, a máquina vinha a ser o resultado da convergência entre técnica, tecnologia e ciência e, de tal modo, fazia-se matéria e corpo da fronteira superada do conhecimento. A máquina adjetivava com valor a ação, o fato e quem a punha a funcionar. No entanto, tanta certeza afirmativa, 
camuflava, sobretudo, a desordem, que o fim de século traduziria em incerteza.

É neste ponto que se retoma a novela de Tiphainge de la Roche, citada em uma revista fotográfica dos anos de 1880 pela admirável coincidência entre o que narra a história e a técnica de registro do colódio ${ }^{6}$, que era, à época, o recurso mais frequente para a obtenção de fotografias. Coloca-se em discussão se por trás da surpresa do articulista, que trata a história como prenúncio de invento e ciência, não se insinua uma ideia, filha da fronteira entre esses dois mundos os quais Baumer nomina de 'neo-iluminista' e 'fin-de-siècle', agentes etéreos do pensamento europeu do século XIX.

\section{A ideia de veridicus visual}

A fotografia é uma invenção europeia, no entanto, não porque a França abraçou a invenção de Daguerre, generosamente oferecendo-a ao mundo e sim porque, inerente ao pensamento europeu oitocentista, uma ideia nutria o desejo da representação feita pela máquina. Aqui se denomina tal ideia de veridicus visual.

Neste prólogo do fim, faz-se bem perguntar e responder o que se entende por fotografia. Não é tão simples defini-la como já o foi no século passado. No presente em que se escreve esse texto, o processo dominante pelo qual a maioria das pessoas obtém fotografias em quase nada é comparável ao que se empregava

\footnotetext{
${ }^{6}$ Embora tanto na obra de Sougez como na A Arte Photographica encontrese definição para o processo do Colódio, o Diccionario Visual de Fotografía, publicado pela editora Blume de Barcelona, em 2010, é sintético e preciso ao esclarecer que esta emulsão, proposta em 1847 pelo escultor Frederick Scott Archer solucionou parte das dificuldades técnicas oferecidas pelo daguerreotipo e calótipo, processos que acabaram sendo suplantados pelo colódio. A principal qualidade desta emulsão (mistura de nitrato de celulose, éter sulfúrico e álcool etílico) era sua aderência, em especial ao vidro, razão pela qual gerou matrizes negativas melhores quanto à definição da imagem.
} 
há poucas décadas. No entanto, ainda aplica-se o vocábulo fotografia pensando-se sobre uma imagem tornada essência, quase naturalizada, tão grande é o reconhecimento que se faz dela e que não semelha distinto daquele que se fazia com o processo anterior. Parece que o processo, para o senso comum, dilui-se diante do resultado. Porém, por quase 160 anos, a palavra fotografia referiu-se a uma imagem obtida por ação da luz sobre material fotossensível processado quimicamente. Considerava-se essa imagem, dada a sua natureza essencial, uma forma de representação ambivalente, que tanto poderia ser o registro objetivo de determinada visão do mundo quanto o produto de uma negociação entre fotógrafo e máquina. Em ocasiões diversas, essas posições foram antagônicas ou evidenciaram a diacronia entre os usos da fotografia e os momentos nos quais tais usos eram interpretados.

A resposta mais adequada a este estudo encontra-se no texto do historiador Michel Frizot (1998, p.11) que se coíbe em tratar desse meio na sua superfície para entendê-lo como resultante de ações de diferentes campos: influências, afinidades, referências, determinações sociais, convenções de interpretação e, também, do determinismo tecnológico. Compreender a fotografia dentro de tal trama de afluências é optar por dar-lhe a condição de um objeto arqueológico que pode ser entendido não pelas diversas camadas de tempo que o envolvem, mas, sim, pelo conjunto de fatores que tanto o fizeram existir como o relegaram ao sepultamento. Então, como diz Frizot (idem) não se deve julgar a fotografia pelo que ela representa e sim o que ela representa em si própria e esse julgamento opera-se quando tal objeto é reencontrado, trazido à superfície novamente e cercado pela aura da promessa de novos sentidos.

Neste trabalho, a abordagem que se faz à fotografia é de significado: o que era a ideia de fotografia no século XIX e o sentido que a novela do escritor francês proporcionou ao aludir que essa ideia poderia existir antes do fato.

Apesar do sucesso que a invenção de Daguerre fez na América, a fotografia era, oficialmente, um invento europeu. $\mathrm{O}$ número de países na Europa que concorria com essa comunidade 
fotográfica oitocentista era grande e pode ser vislumbrado na lista dos Jornaes Photographicos que a revista estudada apresenta no seu primeiro número, separados por países: são sete publicações na França, nove na Inglaterra, uma na Dinamarca, duas na Holanda, uma na Itália, sete na Alemanha, uma na Rússia e aquela que lista como única em Portugal. A essa listagem se somam os anuários que acrescentam mais um país europeu: Áustria e uma referência à "America Ingleza". Ainda na mesma seção, a revista faz uma longa listagem de quatro páginas e meia dos livros em francês, que se dividem em tratados e cursos de processos específicos, além dos textos teóricos e históricos sobre fotografia. Ao longo dos demais números da revista, outros títulos tanto das publicações periódicas quanto de livros, vão sendo apresentados. Ou seja, a listagem que a revista consegue expor não é conclusiva e, talvez, nem tenha sido exaustiva, mas contribui para desenhar a abrangência que os praticantes da fotografia tinham, naquele momento, nesse conjunto de países vizinhos que se entendiam como europeus.

A fotografia, como ideia, afluiu a partir dos anos de 1870 ao pensamento europeu em um período que Baumer (1990, v.2, p. 6263) denomina Neo-iluminista. Como invento, como prática e como discurso, este inédito meio de representação coadunava-se com o culto da ciência e alinhava-se afirmativamente com a nova escola da pintura que se tornou conhecida com o nome de Realismo. Tanto na fotografia como na pintura realista a imagem se constituía sobre e a partir do concreto: aquilo que era real e existente. Não se poderia fotografar algo que não existia fisicamente à frente da câmera, assim como o pintor realista só representava as coisas tangíveis e reais. O pensamento neo-iluminista rechaçava o apriorismo por considerar que o conhecimento a priori fundava-se na lógica errônea que admitia o convencional, a tradição, e até mesmo, o arbitrário. A rejeição ao indeterminado, inerente a essa forma de pensamento, encontrava na concretude do tangível, da experiência testada e da ciência experimental a sua afirmação e a possibilidade de compreender, pelo método, a ordenação e previsibilidade do mundo. Sob esse aspecto, tanto a fotografia como a pintura realista 
$|156|$

A ideia de verdade na fotografia...

poderiam ser entendidas, naquele momento, como atitudes diante da natureza, das quais o resultado era uma imagem.

No entanto, aquilo que carecia à pintura era o que determinava a fotografia: a máquina. Na fotografia, a câmera era o fato gerador, o mecanismo responsável pelo registro, pela visão clara da natureza sem intervenção humana. Era esse o elemento que distinguia e afirmava a fotografia: o meio sem o homem. Evidentemente, era uma ideia, não um fato. Todo o processo fotográfico dos anos oitocentos dependia, intensamente, e na maioria das ocasiões, exclusivamente, da ação humana. Só nos últimos anos do século surgiria a promessa do "você aperta o botão, nós fazemos o resto", lançada como slogan da Kodak na publicidade das primeiras câmeras portáteis para público amador. O investimento vultoso da empresa norte-americana anunciava uma revolução no uso da fotografia que, em termos práticos, levaria alguns anos do século XX para atingir resultados definidores tanto do produto de mercado como do uso social. Assim, nos anos dos quais se fala, a câmera era uma máquina que se operava como uma ferramenta. Em vão o fato não alimentasse a expectativa, a ideia sustentava-se.

Em síntese, o juízo era de que se poderia produzir a verdade a propósito do mundo sobre suportes permanentes, duradouros e assertivos.

O invento dos gênios de Tiphaigne de la Roche, chamado na novela apenas de quadros, reporta a ideia de uma natureza que se faz representar com a mesma acuidade visual do reflexo: nada a mais, nada a menos do que de fato é. Tal abordagem da natureza pode ser depreendida na obra Systmea Naturae de Lineua, escrita e publicada em 1735, da qual Baumer (1990, v.1, p.232) reproduz a frase em que o cientista diz que "A terra é como um espelho no qual o Céu se mostra a si próprio, tal como o homem se reflete nas águas claras". Lineau foi um biólogo atento ao mundo invisível aos olhos que o microscópio revelava e que, segundo Baumer acreditava na permanência das espécies e de tudo o que a natureza apresentava. Há, portanto, dois aspectos associados na teoria deste cientista, que conquistou a atenção do público: há uma 
verdade imutável na natureza e ela pode se revelar pela visão. E, ainda que no momento seguinte, esta teoria perdesse campo para o transformismo, adeptos de grande corporatura, como Voltaire, iriam atualizá-la, ao menos para recusar a hipótese de que o movimento era intrínseco à matéria.

A imutabilidade inscrevia-se, segundo Baumer, em uma ordem que o pensamento do século XVIII desejava sustentar: a ordem eterna das coisas. Enquanto outras teorias surgiam promulgando e refutando hipóteses antagônicas, instalou-se um conflito que o autor observa, em especial, na última década desse século com as publicações de trabalhos notoriamente transformistas de Erasmus Darwin, James Hutton, Pierre Laplace, encerrando com o impactante pronunciamento de Lamarck sobre a evolução. Enquanto isso, "apenas alguns anos antes, o grande Lineau símbolo da fixidez da natureza, fora homenageado com um cortejo fúnebre digno de um rei, e tanto Buffon como Kant tinham se declarado contra o transformismo" (1990, v.1, p. 242).

Tiphaigne de la Roche escreveu sua novela no momento em que o mundo intelectual europeu debatia-se entre teorias conservadoras e revolucionárias. A desordem que iria atravessar o pensamento dos anos oitocentos insinuava-se um século antes, encontrando expressões particulares que surgiam nas ciências, nas artes e na política. Em dado momento, as teorias tanto convergiam como geravam espaços de instabilidade e hiatos no pensamento. Pode ser que a imaginação de um literato intuitivo tenha dado forma a uma ideia que permaneceria até o fato existencial consubstanciar-se.

É possível que antes de Weedgwood, Niépce, Daguerre, Talbot e outros, Tiphaigne tenha percebido que poderia haver um meio de salvar a história da transitoriedade, que tanto se afirmaria como afirmaria ao que referenciava: uma verdade especular, um reflexo permanente do mundo. Mais do que a predição de um processo, os quadros encontrados por Giphantie no reino dos gênios, registravam alegoricamente, a anterioridade de uma ideia, que a fotografia, como processo, meio de representação e resultado, daria corpo: um veridicus para ser visto. 
A ideia de verdade na fotografia..

\section{Bibliografia}

A ARTE PHOTOGRAPHICA. Revista mensal dos progressos da fotografia e das artes correlativas. Porto: Photographia Moderna, v.1, jan.-dez. 1884. Facsímile. Porto: CPF, 2001.

Porto: Photographia Moderna, v.2, jan.-nov. 1885. Facsímile. Porto: CPF, 2001.

BAUMER, F. Le V. O pensamento europeu moderno. Séculos XIX e XX. Lisboa: Edições 70, 1990, v.1, v.2.

FRIZOT, M. The age of light. In FRIZOT, Michael (edit.). A new history of photography. Köln: Kölnemann, 1998, p. 9-14.

STABLEFORD, B. (org.). News from the moon: Nine french protoscience fiction stories from 1768 to 1902. London: Black Coat Press, 2007.

SOUGEZ, M-L. História da fotografia. Lisboa: Dinalivro, 2001. 